\title{
Needs of disabled children and their families
}

\author{
J Milner, C Bungay, D Jellinek, D M B Hall
}

\begin{abstract}
In the new NHS those who provide services for disabled children need to measure and demonstrate their effectiveness, but there are no easily available outcome measures for use by child development centres and teams. The development of an alternative approach, using a series of statements of good practice, is described. Parents of children with cerebral palsy were asked to participate in semistructured interviews, to ascertain the value and relevance of these quality statements. Parents were most concerned about the standard of news breaking and early follow up, the sharing of information, and the supply and repair of equipment. The findings were used to modify the quality checklist and it is proposed that this should form the basis of a 'charter for disabled children and their families'.

(Arch Dis Child 1996;75:399-404)
\end{abstract}

Keywords: child development centre, quality assurance, cerebral palsy.

Chronic disabling conditions of childhood, such as cerebral palsy or learning disability, cannot be cured and professionals aim to help the child and family function in the most effective way possible, as they learn to accept the limitations imposed by a persistent disability. ${ }^{1}$ The development of an evidence base and measurement of quality in the health care of disabled children are, therefore, challenging tasks. ${ }^{2-4}$ The benefits of treatment are controversial and improvements occur slowly. Quality of life measures for disabled people are not yet fully validated. ${ }^{5}$

Alternative approaches to the measurement

St George's Hospital, London

J Milner

C Bungay

D Jellinek

Department of

Community

Paediatrics,

Children's Hospital,

Sheffield S10 2TH

D M B Hall

Correspondence to: Professor Hall

Accepted 31 May 1996 period of 10 years, a checklist of criteria or 'statements of good practice' has evolved for the care of children with special needs, ${ }^{78}$ and has been used ${ }^{9}$ as an aide mémoire for doctors and health visitors, a waiting area notice for parents, and an insert in the personal child health record. The aims of the project reported here were: to further develop the checklist; to determine the extent to which parents considered that these criteria had been fulfilled in their own experience; and to ascertain which criteria were most important to parents. It is proposed that the end product should be regarded as a 'charter for disabled children and their families', which is acceptable to managers and purchasers.

\section{Methods}

The study was carried out during 1991-2 in Wandsworth, an inner London district with a population of 198000 . The group chosen comprised all children living in the district who had a diagnosis of cebral palsy and were under 8 years of age, irrespective of whether or not the child was under the care of a consultant at the district hospital (St George's Hospital). They were identified by various means, including the district special needs register, lists obtained from physiotherapists in the child development team (CDT) and at local schools, and help from a range of other professionals. Each family was approached by letter and invited to participate in a semistructured interview.

Our checklist of quality statements was developed into a questionnaire after reviewing the literature on patient satisfaction, ${ }^{10-12}$ news breaking, ${ }^{13}$ audit, and consumer surveys. ${ }^{14} 15$ The questionnaire incorporated: a variety of open ended questions about satisfaction with services (for example, 'what is good about the service?' and 'what could be better?'); questions about the provision of information and support; a review of specific interventions; and invitations to suggest changes and improvements. It was tested and modified in a neighbouring district. A copy is available on request. All interviews were conducted by one individual (JM) who was not otherwise an employee of the health authority. For ethical reasons only the interviewer knew the identity of each family and therefore no attempt was made to compare the performance of individual professionals or teams. Interviews were tape recorded and transcribed. Quantitative data were analysed using Epi-Info.

Non-responders were sent up to three letters or contacted by telephone. Information on those who did not respond to any contact was obtained by review of case notes. Details of any outstanding litigation or complaints were obtained.

The checklist was revised when the analysis was complete. It was discussed with representatives of the health authority, social services, and the local education authority. Finally, it was presented for comment at a seminar on the management of CDTs. Further changes suggested by the participants were incorporated. 


\section{Results}

Fifty five children met our criteria and all these families were approached. Of these, 39 (71\%) agreed to be interviewed. Fifteen were under the care of consultants in other districts. Ten who declined to be interviewed were contacted by telephone and two of the remaining six responded to a brief postal questionnaire. Reasons given by parents who refused interview (non-responders) included: 'the child does not have any special needs' (four families); 'I have no time to be interviewed' (four); 'nothing would change' (two); and 'discussing past events would be too painful' (two). Children of the non-responders were less disabled than those of the responders (12/16 non-responders were ambulant compared with 18/39 responders), although the difference did not reach statistical significance. Case note review of the non-responders did not reveal any major omissions of service provision and there was no excess of litigation or outstanding complaints in the non-responding group.

The following data and results refer to the 39 families interviewed. Four children were under 2 years of age; 17 were between 2 and 5 years, and 18 were between 5 and 8 years. Twelve had hemiplegia, five diplegia, 14 four limb involvement, and eight were described as mixed or uncertain.

OVERALL LEVELS OF SATISFACTION

Ten families (26\%) were highly satisfied, 10 $(26 \%)$ fairly satisfied, and 15 (38\%) moderately satisfied; two (5\%) gave a 'fairly low' rating and two (5\%) a 'low' rating.

\section{QUALITY OF INFORMATION AND SUPPORT}

Initial consultation and the news breaking process These questions elicited more detailed responses than any other topic. Twelve parents had experienced a short waiting time (less than one week) between referral and first consultation, four waited between one week and one month, and seven waited more than one month. Unexpectedly, few of the latter commented adversely on the delay. In the remaining 16 , no specific date of referral or definitive consultation could be identified, because the baby was in neonatal intensive care or attending regular follow up clinics, so that the diagnosis of cerebral palsy was an 'evolutionary' process. ${ }^{1617}$

Twenty parents were positive about the way in which the situation was handled: ' .. at the time of great anxiety we found SCBU [special care baby unit] helpful which gave us confidence ... it was technically excellent but you really felt they cared for the children ... right from the pathetic days in the incubator until coming home'. Some parents were very grateful for 'good' news breaking. 'People forget the pain ... When we met $\operatorname{Dr} X$ we thought, here is a scientist and he is human'. 'I still get upset about it [but] ... he couldn't have said it any better, it was a sad thing to tell us'.

Eight had some adverse comments and 11 were dissatisfied. 'They just dropped it on me ... I was only 19. They had to phone for my mum because I couldn't cope with it.' 'The doctor said he just had stiff limbs ... I was told very late [ 20 months] which I am so very angry about'. ' ... there was a great reluctance to say [anything to us]. We had made our own diagnosis before anyone dared tell us'. 'I went for what I thought was a normal check-up. They said his brain was the wrong shape and his head wasn't growing'.

Several parents of premature babies noted that delays occurred because they, and sometimes the doctors, overestimated the extent of motor delay attributable to prematurity: 'because he was prem we thought he would catch up'.

Twenty parents $(52 \%)$ thought that the initial prognosis was 'too gloomy': 'they didn't tell me anything positive'; $18(46 \%)$ said it was 'about right'; only one thought it was 'too optimistic'.

\section{Early follow up}

All but one parent reported an offer of an early follow up consultation after news breaking; 10 $(26 \%)$ commented favourably on supportive telephone calls from their doctor or therapist; $31(79 \%)$ were visited by their health visitor or social worker, or both. Most parents valued this support: 'I needed someone to talk to. It has an effect on the child when the mother is depressed'. 'A lot is done for the childrenafter-care is needed for the parents!'

Of the eight who did not receive a visit, four preferred to go to the clinic. Two felt overwhelmed with too much professional support: 'Too many people came'. 'You can't adjust in a short space of time'. The one person with a negative experience was still angry: ' ... there was a real cock-up, they didn't pass the file on and for a month nobody came near me ... it was awful, I went into limbo. The hospital was horrified when they realised and then they never stopped coming!'

\section{Continuity and follow up}

Parents were asked for their views on routine follow up and access to immediate care for acute illnesses. Thirty three parents $(85 \%)$ had a routine follow up at least annually; four of the six who did not would have liked it. Various views were expressed about follow up arrangements: 'I would like an appointment every 6 months even if only for 10 minutes-you do feel slightly abandoned'. Ease of access to their consultant in an emergency was considered important, although 16 parents doubted whether they would find it easy to see their consultant urgently. 'In an emergency I would be able to make an unbooked visit'. '[I would call] $\mathrm{V}$ [the CDT secretary]-she is so important-like the beginning of the medical train'. 'I don't need regular appointments because he is so healthy'.

\section{Knowledge about the child's condition}

Thirty five parents $(90 \%)$ were able to define the child's condition and $30(77 \%)$ had an exact diagnosis. Three wanted a brain scan even though they knew that it was medically unnecessary. One wanted more tests but noted that 'MRI and the blood tests [enzyme studies 
etc] could have been done sooner, but the hold up came from us, they have been good at going along at our pace'. Only two thought that a diagnosis was unimportant. Three felt that more effort should have been made to establish a diagnosis.

\section{Written report}

Parents were asked whether they had received written reports about their child and how easy they were to understand. Thirty one parents $(79 \%)$ had received a written report; 24 of these found it easy to understand and were satisfied but a few found it difficult: 'the health visitor had to explain it to me'. Most $(32,82 \%)$ felt that reports and information should be shared with other members of the CDT and the doctor, but there were some caveats: 'depends on whether [the information was] medical-I would not want everyone to know about my emotional state'. 'I don't mind it being shared but I would like a little privacy if there is something to be told'. 'Outside the department it might be polite to ask us'.

\section{Medication knowledge}

Parents of the 14 children receiving medication knew the reasons for treatment; nine could list the possible side effects and 11 knew the planned duration of treatment.

\section{Parental understanding of treatment}

All families claimed to understand the type and aims of physiotherapy; six identified conductive education as their child's main programme, eight Bobath; but 24 did not know that their therapists were using a Bobath based programme. Eleven were dissatisfied with the quantity of treatment. Many parents felt that they had not been consulted or informed about treatment options; only eight knew how the choice of treatment programme had been reached. By contrast, many were articulate and well informed. 'I investigated the Peto Institute ... it was months before I realised it would not be for my child. The physios have been very sniffy about it anyway-along the lines of, anyone is going to benefit if they have that amount of therapy. This is logical but what is wrong with having that amount?' 'Physios seem to be Bobath trained-but I wonder why ..?' 'I don't want to feel later that my child wasn't given the opportunity to try things'

\section{Establishing contacts}

We asked whether a meeting with another family with a similar child had been offered and when would have been the optimal time for this contact. Eighteen families (46\%) were in touch with one or more other families or voluntary organisations, or both, and 14 of these had obtained the details from the CDT; 20 families (51\%) did not belong to any organisation because they 'were too busy' or 'did not want to'. Views on timing varied widely: 'It would have been helpful at diagnosis'. 'Just after it had sunk in'. 'I didn't accept because I was still a bit angry and frustrated'. 'I found out about it but I didn't want to talk to them for many months until I was ready'. Several commented on the importance of a well matched family: '... their child might not have been quite the same and that would have been harder'. '... they may have a quieter child and then I would land up feeling depressed'.

\section{Educational services}

Questions about the 1981 Education Act elicited much dissatisfaction. 'It is a nightmare of words'. 'It is too complicated for normal people to cope with'. 'They write about him like he is a machine not a person'. 'There is a political war with the educational psychologist'. Parents expressed a range of views about the best time to discuss going to school. Only seven felt that it should be very early: 'Under 2 -it should have been sooner, no-one discussed it with me'. The remainder thought that it should be between 2 and 4: 'They discussed it at 2 , it should have been later, you wouldn't send an able bodied child to nursery school at 2 '. In contrast, most parents were satisfied with the educational provision offered. In particular, the Portage programme had been used by $13(33 \%)$ and was highly praised by 12 .

\section{SPECIFIC MEDICAL AND TREATMENT}

INTERVENTIONS

Only 11 parents $(28 \%)$ felt that they had received advice about genetic aspects. Thirty eight parents $(97 \%)$ reported that the child had undergone a hearing assessment and 37 (95\%) a vision assessment. Twenty four children $(62 \%)$ had been referred for dental advice. Eighteen of the 19 children with four limb cerebral palsy or diplegia had had hip radiography. Thirty seven (95\%) were fully immunised. Twenty children ( $51 \%$ ) had been regularly measured.

Thirty four parents $(87 \%)$ had used one or more items of equipment. Nine commented about lack of choice, 15 about delays in getting equipment or having it repaired, or both, and four on not being kept informed: 'there wasn't any choice-I have never been asked about colour'. 'Seven months is a long time to wait for a double buggy'. 'He grew out of his chair before he had it!' I have to keep chasing'.

\section{IMPROVEMENTS SUGGESTED BY PARENTS AND} SEMINAR MEMBERS

Table 1 summarises the views of parents on how services could be improved. Table 2 shows the final version of the checklist.

\section{Discussion}

Surveys are likely to overestimate parent satisfaction. Families who were not ascertained for the survey or who declined to participate might be more likely to be disaffected with health professionals, or to be embroiled in medicolegal proceedings. We expected to identify about 60 children with cerebral palsy given a birth prevalence of 2.5 per 1000 ; the actual value of 55 suggests that ascertainment was reasonably complete. The most frequent reason for non-participation appeared to be that parents did not wish their child to be medicalised' or 'labelled' as having special needs, ${ }^{18}$ although 
Table 1 Parents'suggestions and proposed response by the child development team

\begin{tabular}{|c|c|}
\hline Parent's suggestion & Proposed response \\
\hline Access to services at hospital & More disabled parking bays to be created \\
\hline $\begin{array}{l}\text { Better coordination within team and between agencies; better } \\
\text { and earlier introduction to the Education Act; closer liaison } \\
\text { with social services and voluntary agencies }\end{array}$ & $\begin{array}{l}\text { Creation of a multiagency centre for children with special } \\
\text { needs, outside the hospital campus, to facilitate planning and } \\
\text { monitoring }\end{array}$ \\
\hline More information about services & Preparation of a new loose leaf handbook \\
\hline More, and more flexible, respite care & $\begin{array}{l}\text { Review of existing users of respite, to identify more appropriate } \\
\text { facilities; negotiation with community nursing management } \\
\text { and with social services to develop available services and } \\
\text { provide support care at home }\end{array}$ \\
\hline $\begin{array}{l}\text { Better liaison between health, education, and social services } \\
\text { for children needing residential schooling or care }\end{array}$ & $\begin{array}{l}\text { Agreed with health authority to set up an advisory group with } \\
\text { education and social services representatives, to facilitate } \\
\text { decisions about funding }\end{array}$ \\
\hline $\begin{array}{l}\text { Physiotherapy to continue during school holidays (school } \\
\text { aged children) }\end{array}$ & $\begin{array}{l}\text { Video of treatment sessions for parents, for reference when } \\
\text { treating the child at home }\end{array}$ \\
\hline More choice in equipment and therapy & $\begin{array}{l}\text { Resource library within the child development centre (books } \\
\text { and videos): short term loan service for equipment. } \\
\text { Establishment of interagency database }\end{array}$ \\
\hline Difficulty in understanding written reports & Tape record consultations and conferences \\
\hline
\end{tabular}

four parents seemed to be disillusioned with all professional services.

The number of parents who can be consulted using semistructured interviews is much smaller than with a postal questionnaire, as used by Rosenbaum et al in a survey with similar aims, ${ }^{4}$ but the method provides more detailed insights into parents' views. Asking people to identify 'critical incidents' and the use of open questions such as 'what was good about the experience' helped to assess parental satisfaction ${ }^{19}$ and to determine which factors were most important to parents. ${ }^{20}$

Topics that elicited particularly detailed and articulate responses and seemed to be the most important to parents included the process of news breaking and early follow up, the sharing of information, and problems with equipment. $^{21}$

The importance of the news breaking process is supported by other research ${ }^{22}$ and voluntary organisations. ${ }^{23}$ Good practice has been well defined but it is clear that there is still room for improvement. Parents' comments suggested that the quality of news breaking and early counselling were not only important to them directly, but they also affected their ability to work effectively with the child.

Parents expressed concerns about sharing and ownership of information. They repeatedly mentioned their right to be told about the doctors' concerns and the available management options, and they emphasised their dissatisfaction when they felt that this had not been provided early enough, or in sufficient detail. ${ }^{24}$ The right to be consulted about sharing personal information was also important to some parents. ${ }^{25}$

There was no consensus about the type of follow up required, or the timing of education advice and information about voluntary agencies. Thus it is vital to consult with and listen to parents to determine what they want. Families do not want decisions to be taken out of their hands by staff withholding information. 'Parent empowerment' models of practice ${ }^{26}$ require that parents need information, and an understanding of the reasoning behind the professionals' recommendations and treatment, to make informed decisions in the best interests of their child. It is a sign of successful 'empowerment' when parents debate and comment on the relative merits of different systems of treatment or items of equipment and feel free to try other methods.

Equipment is provided by several health service budget holders, the education authority, and social services. ${ }^{27}$ The division of responsibility often causes delays and much irritation and stress are caused by this problem. Its resolution should be regarded by managers and purchasers as a matter of urgency.

There was room for improvement in some areas which should be regarded as routine. There were delays in arranging the first consultation after referral. Some written reports were hard to understand. The Education Act had not always been properly explained.

Dissatisfaction with treatment input seemed to be a less prominent issue than we had anticipated. ${ }^{28-30}$ It is unclear why some parents seek additional treatment or investigate other systems such as conductive education, while others accept what they are offered. Remarkably, few parents understood that most therapists were trained in the Bobath school, suggesting that therapists may 'undersell' the sophisticated system in which they are trained.

\section{Conclusions}

We suggest that the final checklist may offer a useful standard against which other CDTs and managers can review performance and compare different models of CDT staffing and structure.

Our findings suggest that high standards for the initial consultation, news breaking and early follow up, coupled with a respect for parents' rights to information, are crucial. In contrast to Sloper and Turner, ${ }^{31}$ our interview data suggested that parents' satisfaction with these aspects of care seemed to affect their satisfaction with investigation and treatment. This issue merits further study.

We thank parents and colleagues who participated; the director of audit (Dr Littlejohns); members of the health authority social services, and the education authority who cooperated with the study; and Ciba Geigy for supporting the seminar on CDTs held on 18 and 19 November 1995. 
Table $2 A$ charter for disabled children and their families

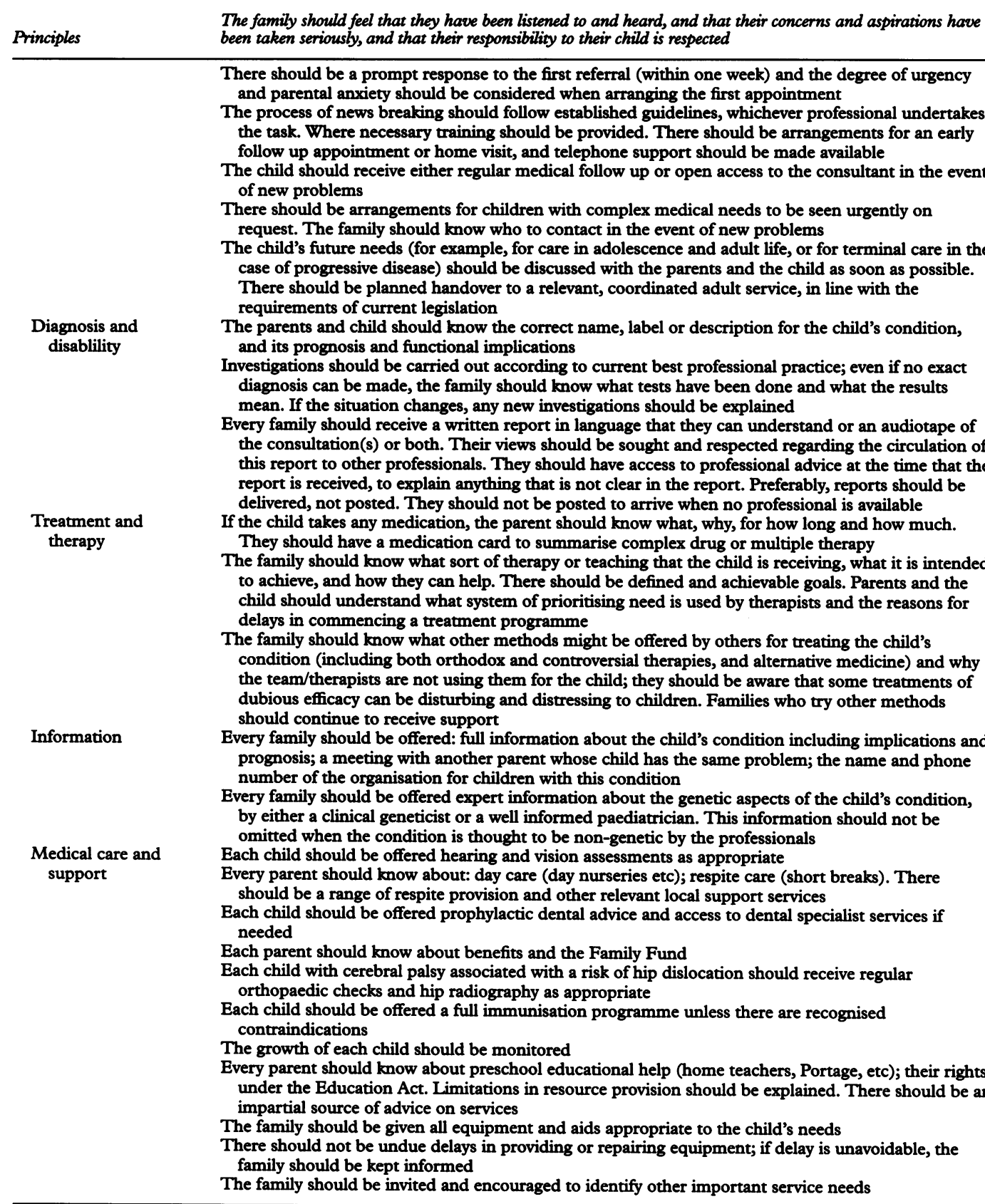

1 Robards M. Running a team for disabled children and their families. Clinics in Developmental Medicine No 130. London: Mackeith Press, 1993.

2 British Paediatric Association. Clinical audit in paediatrics. London: British Paediatric Association, 1991.

3 Berwick DM. Heal thyself or heal thy system: can doctors help to improve medical care? Quality in Health Care 1992;1 suppl:S2-8.

4 Rosenbaum PL, King SM, Cadman DT. Measuring processes of caregiving to physically disabled children and processes of caregiving to physically disabled ch
families. Dev Med Child Neurol 1992;34:103-14.

5 Lindstrom B. Quality of life for children and disabled children based on health as a resource concept. $\mathcal{F}$ Epidemiol Community Health 1994;48:529-30.

6 Berwick DM. Continuous improvement as an ideal in health care. N Engl f Med 1989;320:53-6.

7 Quine L, Pahl J. First diagnosis of severe handicap: a study of parental reactions. Dev Med Child Neurol 1987;29:232-42.

8 Cunningham CC, Morgan PA, McGucken RB. Down's syndrome: is dissatisfaction with disclosure of diagnosis inevitable? Dev Med Child Neurol 1984;26:33-9.

9 Hall DMB, Hill P. Community child health services. In Stevens A, Raftery J, eds. Health care needs assessment. Oxford: Radcliffe, 1994:517-8.

10 Fitzpatrick R. Surveys of patient satisfaction: I-important general considerations. $B M F$ 1991;302:887-9.

11 Fitzpatrick R. Surveys of patient satisfaction: II-designing a questionnaire and conducting a survey. BMY 1991;302: 1129-32.

12 Hopper A. Quality assurance in outpatient departments. Health Services Management October 1991:216-8.
13 Quine L, Rutter DR. First diagnosis of severe mental and physical disability: a study of doctor-parent communications. F Child Psychol Psychiatry 1994;35:1273-87.

14 Pollitt C. Doing business in the temple? Managers and quality assurance in the public services. Public Administration 1990;68:435-52.

15 Stallard P, Lenton S. How satisfied are parents of pre-schoo children who have special needs with the services they receive? Child Care Health Dev 1992;18:197-205.

16 Cottrell DJ, Summers K. Communicating an evolutionary diagnosis of disability to parents. Child Care Health Dev 1990;16:211-8.

17 Quine L, Pahl J. First diagnosis of severe mental handicap: characteristics of unsatisfactory encounters between doctors and parents. Soc Sci Med 1986;22:53-62.

18 Working Group on Definitions of Disability in Childhood. Disability in childhood: towards nationally useful definitions. London: British Association for Community Child Health and Department of Health, 1994.

19 Carr-Hill RA. The measurement of patient satisfaction. $f$ Public Health Med 1992;14:236-49.

20 Pryce-Jones $M$. Critical incident technique as a method of assessing patient satisfaction. In: Fitzpatrick $R$. Hopkins A eds. Measurement of patients' satisfaction with their care. London: Royal College of Physicians, 1993:87-97.

21 Hall DMB, Hill P. The child with a disability. Oxford: Blackwells, 1995:101-15.

$22 \mathrm{Krahn} G \mathrm{G}$, Hallum A, Kime C. Are there good ways to give bad news? Pediatrics 1993;91:578-82.

23 Leonard A. Right from the start. London: Spastics Society, 1994. 
24 Nursey AD, Rohde JR, Farmer RDT. Ways of telling new parents about their child and his or her mental handicap: a comparison of doctors' and patients' views. Fournal of Mental Deficiency Research 1991;35:48-57.

25 Carman D, Britten N. Confidentiality of medical records: the patients' perspective. Br $\mathcal{F}$ Gen Pract 1995;45:485-8.

26 Appleton Pl, Minchom PK. Models of parent partnership and child development centres. Child Care Health Dev 1991;17:27-38.

27 ICAC. Initiative on communication aids for children-final report. London: AFASIC (Association For All Speech
Impaired Children), 1995.

8 Zahir M, Bennett S. Review of child development teams. Arch Dis Child 1994;70:224-8.

29 White M, Bungay C, Gabriel H. Guide to early movement skills. Windsor: NFER Nelson, 1994

$30 \mathrm{McConachie} \mathrm{H}$. Implications of a model of stress and coping for services to families of young disabled children. Child Care Health Dev 1993;19:37-46.

31 Sloper $P$, Turner $S$. Determinants of parental satisfaction with disclosure of disability. Dev Med Child Neurol 1993;35: 816-25.

\section{Hullabaloon in Uranus}

Some people blow things up out of all proportion, don't they? There are those who maintain that children's party balloons should be banned because children have choked on them. Others with a more fertile imagination spend their tea breaks thinking of something to do with them. Well, you could, for instance, stick them into children's rectums and fill them up with water. There's an idea worth savouring over your morning doughnuts.

That is what happened to 321 children in Iowa City whose parents complained of their constipation and encopresis (Vera Loening-Baucke, fournal of Pediatrics 1996; 128:33640). The hypothesis being tested was that those who were able to push the space invader back at the outside world within five minutes might do better as regards their bowel problem. Well, they didn't; not reliably so at least. After a year $51 \%$ of balloon ejectors and $34 \%$ of balloon retainers had recovered but the with a $51 \%$ positive predictive value, the author concludes, 'the test could not reliably predict recovery'. I'm prompted to wonder what one of Iowa's currently best known sons would make of it all. ${ }^{1}$

ARCHIVIST

1 Bryson B. The lost continent. London: Abacus, 1990. 